\title{
Sulfonated graphenes catalyzed synthesis of expanded porphyrins and their supramolecular interactions with pristine graphene
}

\author{
SWETA MISHRA, SMRITI ARORA, RITIKA NAGPAL \\ and SHIVE MURAT SINGH CHAUHAN* \\ Bioorganic Laboratory, Department of Chemistry, University of Delhi, Delhi 110 007, India \\ e-mail: smschauhan@chemistry.du.ac.in
}

MS received 15 March 2014; revised 29 May 2014; accepted 04 June 2014

\begin{abstract}
A newer synthesis of sulfonic acid functionalized graphenes have been developed, which have been characterized, examined as heterogeneous solid acid carbocatalyst in the synthesis of selected expanded porphyrins in different reaction conditions. This environment-friendly catalyst avoids the use of toxic catalysts and enhances the yields of porphyrinoids. The non-covalent interaction of porphyrinoids has also been studied with exfoliated graphene solution in organic solvents by UV-Visible and fluorescence spectroscopy.
\end{abstract}

Keywords. Sulfonated graphene; expanded porphyrins; heterogeneous catalysis; solid acid; non-covalent interaction.

\section{Introduction}

Graphene, an important allotropic member of carbon, has received much attention owing to its interesting properties in material science with wide range of applications in energy devices, electronics, catalysis, sensors, reinforced composites and biomedicines. ${ }^{1-6}$ Several effective techniques developed for preparing graphene sheets limit their biological applications due to the insolubility of graphite or graphene. ${ }^{7}$ Several authors have tried chemical functionalization to prevent the agglomeration of single layer graphene and maintain the inherent properties of graphene. ${ }^{8}$

Porphyrins are ubiquitous pigments in nature and play key roles in biological processes. ${ }^{9}$ They have also emerged as functional dyes, non-linear optical materials, ion receptors and stable organic radicals. ${ }^{10-12}$ Porphyrins consist of four pyrrole rings connected by meso-methine bridges, while the name 'expanded porphyrin' stems from their larger number of pyrrole rings. ${ }^{13-17}$ These expanded porphyrins explain the difference between aromatic, stable antiaromatic species and conformationally twisted Möbius aromatic species. ${ }^{18}$ Earlier, expanded porphyrins have been synthesized by simple Rothemund-Lindsey protocol that involves $\mathrm{BF}_{3} . \mathrm{OEt}_{2}$ catalyzed condensation of pyrrole and 2,3,4,5,6-pentafluorobenzaldehyde in dichloromethane and subsequent oxidation with 2,3dichloro-5,6-dicyano-1,4-benzoquinone (DDQ). ${ }^{12}$ Recently, we have reported the synthesis of dipyrromethanes

\footnotetext{
*For correspondence
}

and calix[4]pyrroles using graphite oxide as solid acid catalyst in different reaction conditions. ${ }^{19}$ Next focused on the synthesis of sulfonic acid functionalized graphene via bulk functionalization by direct exfoliation of graphite. Here, we report the synthesis of porphyrins and expanded porphyrins catalyzed by these sulfonated graphene based solid acids, to the best of our knowledge for the first time. These solid acids are eco-friendly and recyclable up to five times.

\section{Experimental}

\subsection{Synthesis of sulfonated graphene}

Graphite (100 mg) was exfoliated using ultrasonication for $2 \mathrm{~h}$. (1\% wt) SDS was added to the reaction mixture. Diazonium salt of sulfanilic acid was synthesized using $\mathrm{HBF}_{4}$ and sulfanilic acid. Diazonium salt (35 mg, 0.13 mmol) was added to graphite suspension and stirred for $16 \mathrm{~h}$ at $35^{\circ} \mathrm{C}$. After centrifuging and rinsing with water several times and the product was dried in vacuum at $50^{\circ} \mathrm{C}$. FTIR (KBr, cm $\left.{ }^{-1}\right) 3437$ (br), 1194, 1126, 1036, 1005, 820; Raman shift ( $\left.\mathrm{cm}^{-1}\right)$ : 1354 (D band), 1581 (G band) $\mathrm{I}_{\mathrm{D}} / \mathrm{I}_{\mathrm{G}}=0.32$.

\subsection{Reaction of pyrrole with aryl aldehydes in presence of different carbocatalyst}

2.2a Method A: Reaction of pyrrole with aryl aldehyde: A mixture of pyrrole $(276 \mu \mathrm{L}, 4 \mathrm{mmol})$ and 
aldehyde (4 mmol) and sulfonated graphene 4 (170 mg) in o-DCB $(60 \mathrm{~mL})$ was stirred at room temperature under inert atmosphere for $2 \mathrm{~h}$ followed by addition of DDQ with further stirring for $2 \mathrm{~h}$. Progress of reaction was monitored by TLC. After completion of reaction, catalyst was filtered and rinsed with chloroform followed by ethanol. DDQ (10 g) was then added in the reaction mixture with further stirring for $2 \mathrm{~h}$. Reaction mixture was passed through a short alumina plug and then chromatographed on silica gel 60-120 mesh (9:1 hexane: ethyl acetate) to obtain mixture of desired products leaving behind the polymeric materials. Repeated chromatography of the mixture was done on silica gel using hexane and chloroform (4:6) as eluent to obtain purple $\left(R_{\mathrm{f}}=0.8\right)$, blue $\left(\mathrm{R}_{\mathrm{f}}=0.6\right)$, violet $\left(\mathrm{R}_{\mathrm{f}}=0.5\right)$, red $\left(R_{f}=0.3\right)$ and dark green fraction $\left(R_{f}=0.1\right)$ solid. Mixture of hexaphyrins was further separated by preparative TLC.

2.2b Method B: Reaction of dipyrromethane with aryl aldehyde: A mixture of dipyrromethane $(2 \mathrm{mmol})$, aryl aldehyde ( $2 \mathrm{mmol})$ and sulfonated graphene 4 (170 $\mathrm{mg})$ in o-DCB $(30 \mathrm{~mL})$ was taken in a round bottom flask under inert atmosphere for $2 \mathrm{~h}$. Progress of reaction was monitored by TLC. After completion of reaction, catalyst was filtered and rinsed with chloroform followed by ethanol. DDQ (10 g) was then added in the reaction mixture with further stirring for $2 \mathrm{~h}$. Reaction mixture was passed through a short alumina plug and then chromatographed on silica gel 60-120 mesh (9:1 hexane:ethyl acetate) to obtain mixture of desired products leaving behind the polymeric materials. Repeated chromatography of the mixture was done on silica gel using hexane and chloroform (4: 6) as eluent to obtain purple, blue, violet and green coloured fractions. Mixture of hexaphyrins was further separated by preparative TLC.

\subsection{Non-covalent interaction of porphyrinoids with graphene in organic solvents}

Graphite $(50 \mathrm{mg})$ was ultrasonicated in o-dichlorobenzene $(50 \mathrm{~mL})$ for $5-6 \mathrm{~h}$. The graphene dispersion was centrifuged at 10,000 rpm for $30 \mathrm{~min}$ and the supernatant was collected. Stock solutions of $1.0 \times 10^{-3} \mathrm{M}$ were prepared by dissolving different porphyrinoids in o-DCB. To study the effect, exfoliated graphene $(0.25$ $\mathrm{mg} / \mathrm{mL}$ ) was added to $20 \mu \mathrm{l}$ stock solutions of porphyrinoids and the changes in absorption spectra were recorded after every addition.

\section{Results and Discussion}

\subsection{Synthesis of catalysts}

Diazonium salt was used in the chemical modifications of graphite and graphene oxide. ${ }^{20,21}$ Sulfonated graphene 3 has been synthesized by diazotisation of $r$ GO (scheme 1). Bulk functionalization of graphite was done by exfoliating graphite in $1 \mathrm{wt} \%$ aqueous solution of SDS under ultrasonication followed by the reaction with tetrafluoroborate diazonium salt of sulfanilic acid at $35^{\circ} \mathrm{C}$ for $16-18 \mathrm{~h}$ to give 4 (scheme 2). SDS was added to bring the water-soluble, cationic diazonium reagents in close proximity of the highly hydrophobic graphene sheets. The prepared catalysts were characterized completely by Raman, FTIR, TEM, SEM, XRD and TGA techniques.

\subsection{Characterization of catalysts}

Raman spectroscopy is a powerful tool for characterizing materials possessing conjugated carbon $\mathrm{sp}^{2}$ hybridized bonds, such as graphene, due to their intense Raman signals. The corresponding spectrum for sulfonated graphene $\mathbf{4}$ shows a red shifted D band with increased intensity at $1351 \mathrm{~cm}^{-1}$ indicating disruption of the $\mathrm{sp}^{2}$ carbon network as a result of functionalization $\left(\mathrm{I}_{\mathrm{D}} / \mathrm{I}_{\mathrm{G}}=0.42\right.$ for 4 vs 0.19 for exfoliated graphene), ${ }^{22} \mathrm{G}$ band at $1585 \mathrm{~cm}^{-1}$ and a blue shifted $2 \mathrm{D}$ band at $2720 \mathrm{~cm}^{-1}$ with respect to pristine graphite (figure S4). ${ }^{23}$ Functionalization was further confirmed by IR spectroscopy and elemental analysis. IR spectrum show peaks at $1194 \mathrm{~cm}^{-1}, 1126 \mathrm{~cm}^{-1}$, and $1036 \mathrm{~cm}^{-1}$ (two $v_{\mathrm{S}-\mathrm{O}}$ and one $v_{\mathrm{S}-\text { phenyl }}$ ), $1007 \mathrm{~cm}^{-1}\left(v_{\mathrm{C}-\mathrm{H}}\right.$ in-plane bending) and $830 \mathrm{~cm}^{-1}$ (out-of-plane hydrogen wagging) are characteristic vibrations of a phenylsulfonic acid group (figure S5) ${ }^{24}$ In elemental analysis, the sulphur content was estimated to be $1.5 \%$ in $\mathbf{4}$ and $0.8 \%$ for 3 (table S1). The amount of sulfonic acid groups covalently anchored onto the graphene lattice was calculated by conductometric titration. The $\mathrm{pH}$ and sulfonic acid content in catalyst $\mathbf{4}$ was found to be 2.9 and $55.71 \mu \mathrm{mol} / \mathrm{g}$ respectively (which was five times higher as compared to 3) (Eq. 1) showing high acidic content and proving it to be a better catalyst as shown by results.

Pristine graphite is thermally stable up to $800^{\circ} \mathrm{C}$ under nitrogen. The TGA graph (figure S8) of 4 revealed a weight loss, in the temperature range of 200$500^{\circ} \mathrm{C}$, which is attributed to the thermal decomposition of sulfonic acid groups attached to graphene sheets. ${ }^{3,25}$ The weight loss that occurred above $500^{\circ} \mathrm{C}$ is due to the thermal decomposition of defects created at the time of 


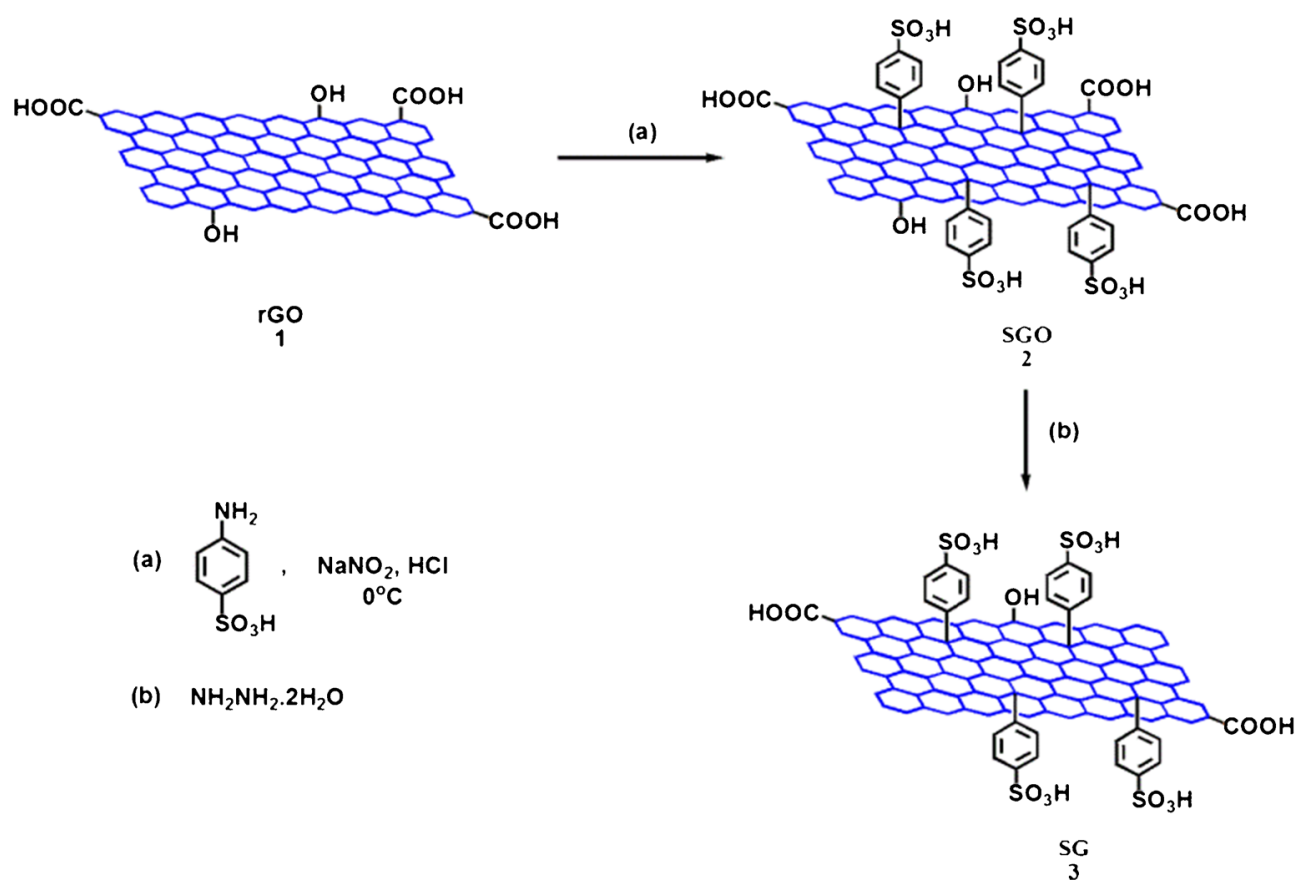

Scheme 1. Synthesis of sulfonated graphene using reduced graphene oxide.

functionalization. The XRD analysis exhibits that the (002) diffraction peak of graphite appears at $26.6^{\circ}$, and the interlayer spacing is $0.34 \mathrm{~nm}$ which was increased to $0.38 \mathrm{~nm}$ in $\mathbf{4}$ after functionalization (figure S7). SEM and TEM images of $\mathbf{4}$ showed that material exhibited crumpled sheet like appearances despite of the presence of functional groups (figure S2, S3). ${ }^{26}$

\subsection{One-pot synthesis of porphyrins and expanded porphyrins}

Firstly, we tried to mimic the Rothemund-Lindsey protocol involving reaction of pyrrole and aldehyde 6a (reactant concentration $10 \mathrm{mM}$ ) in dichloromethane which gave corresponding porphyrinogen in presence of sulfonated graphenes and on oxidation with DDQ gave the corresponding tetraarylporphyrin (8a) while the same reaction when carried out with higher reactant concentration $(67 \mathrm{mM})$ gave a mixture of products which were separated by repeated column chromatography and preparative TLC to give tetraarylporphyrin (8a), N-fused pentaphyrin (9a), hexaphyrin (10a) and octaphyrin (11a) in 20, 8, 14 and $1 \%$ yield (scheme 3 ). The synthesized products were characterized by UV-Vis, ${ }^{1} \mathrm{H}$ NMR and mass spectrometry (figure S9-S18).

Among the prepared catalysts, catalyst 4 showed higher yields of porphyrins and expanded porphyrins as compared to $\mathbf{3}$ and $\mathbf{2}$ (table 1, entry 1-3). Other solid acids such as Amberlyst-15, humic acid and graphene oxide gave only corresponding porphyrin or dipyrromethane and no higher homologues were observed (table 1 , entry $7,8,9$ ). Reaction conditions of this cyclo-oligomerization were then optimized using different solvents and temperature. Among the solvents listed in table 2, o-dichlorobenzene gave very high
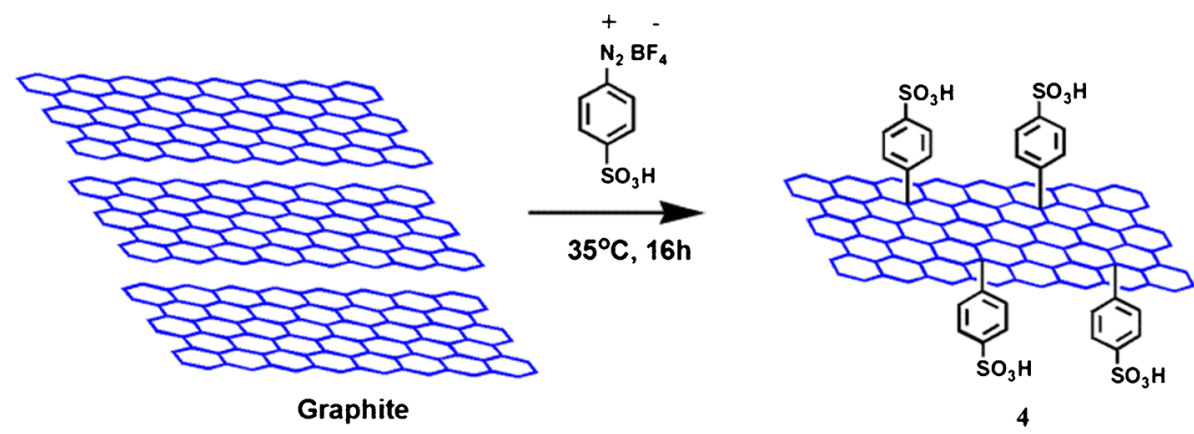

Scheme 2. Sulfonation of graphite using diazonium salt based ionic liquid. 


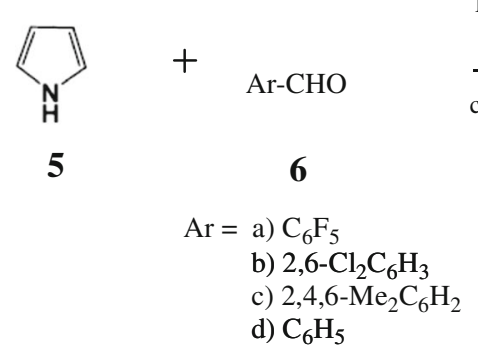

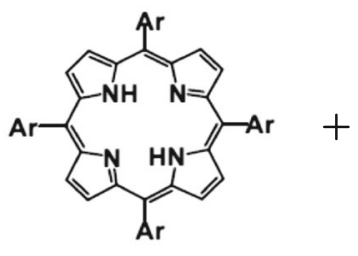

8

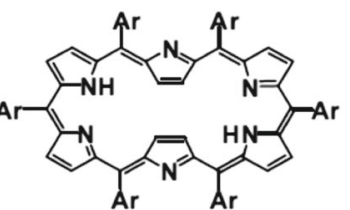

10
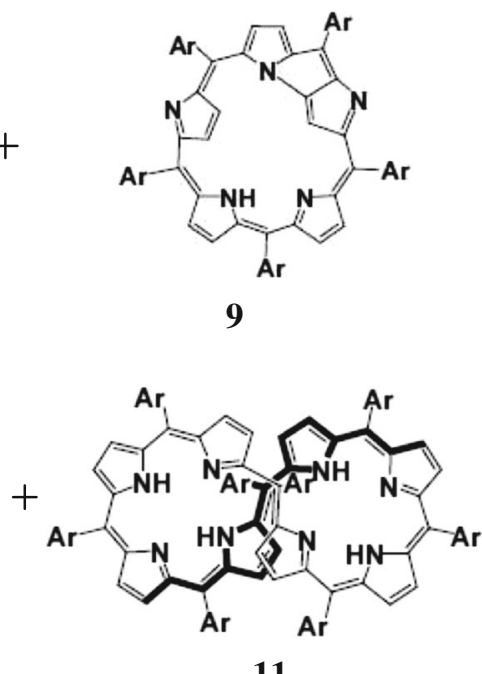

11

Scheme 3. Synthesis of porphyrinoids in presence of sulfonated graphene 4 in different reaction conditions.

Table 1. Reaction of pyrrole and aldehyde (6a) in dichloromethane using various acids [a]

\begin{tabular}{lcc}
\hline Entry & Catalyst & Product Distribution (\% Yield) ${ }^{[\mathrm{b}]}$ \\
\hline 1 & $\mathbf{4}$ & $\mathbf{8 a}\left(\mathbf{2 0 , 1 2} \mathbf{1}^{[\mathbf{c}]}\right), \mathbf{9 a}\left(\mathbf{8}, \mathbf{1}^{[\mathbf{c}]}\right), \mathbf{1 0 a}\left(\mathbf{1 4}, \mathbf{9}{ }^{[\mathbf{c}]}\right), \mathbf{1 1 a}(\mathbf{1})$ \\
2 & 3 & $8 \mathrm{a}(10), 9 \mathrm{a}(3), 10 \mathrm{a}(12), 11 \mathrm{a}($ traces $)$ \\
3 & 2 & $8 \mathrm{a}(10), 9 \mathrm{a}(1), 10 \mathrm{a}(12), 11 \mathrm{a}($ traces $)$ \\
4 & $\mathrm{BF}_{3} . \mathrm{OEt}_{2}$ & $8 \mathrm{a}(12), 9 \mathrm{a}(15), 10 \mathrm{a}(18), 11 \mathrm{a}(5)+$ higher homologue \\
5 & Methane sulfonic acid & $8 \mathrm{a}(14), 9 \mathrm{a}(10), 10 \mathrm{a}(20), 11 \mathrm{a}(4)+$ higher homologue \\
6 & $p-$ toluene sulfonic acid & $8 \mathrm{a}(10), 9 \mathrm{a}(8), 10 \mathrm{a}(15), 11 \mathrm{a}(1)$ \\
7 & Amberlyst-15 & $8 \mathrm{a}(20), 9 \mathrm{a}(1), 10 \mathrm{a}(5)$ \\
8 & Humic acid & $7 \mathrm{a}$ \\
9 & GO & $7 \mathrm{a}$ \\
\hline
\end{tabular}

[a] Reaction was conducted under inert atmosphere, reaction time: 2 h, rt. [b] 8: porphyrin, 9: N-fused pentaphyrin, 10: hexaphyrin, 11: octaphyrin, Isolated yields. [c] Yield after five runs.

Table 2. Reaction of pyrrole and aldehyde (6a) in different solvents using sulfonated graphene $4^{\text {[a] }}$

\begin{tabular}{lll}
\hline Entry & Solvent & Product Distribution (\% Yield ${ }^{[\mathrm{b}],[\mathrm{c}]}$ \\
\hline 1 & $\mathrm{CH}_{2} \mathrm{Cl}_{2}$ & $8 \mathrm{a}(20), 9 \mathrm{a}(8), 10 \mathrm{a}(14), 11 \mathrm{a}(1)$ \\
2 & $\mathrm{CHCl}_{3}$ & $8 \mathrm{a}(18), 9 \mathrm{a}(5), 10 \mathrm{a}(15), 11 \mathrm{a}(1)$ \\
3 & $\mathbf{0 - D i c h l o r o b e n z e n e}$ & $\mathbf{8 a}(\mathbf{1 0}), 9 \mathrm{a}(\mathbf{1 5}), \mathbf{1 0 a}(\mathbf{2 5}), \mathbf{1 1 a}(\mathbf{5})$ \\
4 & $1,2,4-$ Trichlorobenzene & $8 \mathrm{a}(5), 9 \mathrm{a}(8), 10 \mathrm{a}(10), 11 \mathrm{a}($ traces $)$ \\
5 & $\mathrm{DMF}$ & - \\
6 & $\mathrm{NMP}$ & - \\
7 & THF & - \\
8 & MeOH & - \\
9 [d] & No Solvent & $8 \mathrm{a}(8), 10 \mathrm{a}(5), 12 \mathrm{a}(6)$ and other products $[\mathrm{e}]$
\end{tabular}

[a] Reaction was conducted under inert atmosphere, reaction time: 2 h, rt. [b] 8: porphyrin, 9: Nfused pentaphyrin, 10: hexaphyrin, 11: octaphyrin, 12: corrole. [c] Isolated yields. [d] Reaction time: $1 \mathrm{~h}, 80^{\circ} \mathrm{C}$. [e] open chain compounds and polymer.

yields of expanded porphyrins, $\mathrm{N}$-fused pentaphyrin (9a), hexaphyrin (10a) and octaphyrin (11a) in 15, 25, $5 \%$ yield, due to effective dispersion of catalyst and thus providing high surface area while expanded porphyrins were not observed in basic and polar solvents (DMF, NMP, THF). 
Table 3. Reaction of pyrrole and different aryl aldehyde in dichloromethane using catalyst $\mathbf{4}^{\text {[a] }}$

\begin{tabular}{lll}
\hline Entry & Aldehyde & Product Distribution (\% Yield) $[\mathrm{b}],[\mathrm{c}]$ \\
\hline 1 & $6 \mathrm{a}$ & $8 \mathrm{a}(20), 9 \mathrm{a}(8), 10 \mathrm{a}(14), 11 \mathrm{a}(1)$ \\
2 & $6 \mathrm{~b}$ & $8 \mathrm{~b}(15), 9 \mathrm{~b}($ traces $), 10 \mathrm{~b}(5)$ \\
3 & $6 \mathrm{c}$ & $8 \mathrm{c}(11)$ \\
4 & $6 \mathrm{~d}$ & $8 \mathrm{~d}(8)$ \\
\hline
\end{tabular}

[a] Reaction was conducted under inert atmosphere, reaction time: $2 \mathrm{~h}$, rt. [b] 8: porphyrin, 9: $\mathrm{N}$-fused pentaphyrin, 10: hexaphyrin, 11: octaphyrin. [c] Isolated yields.

Reaction of pyrrole with different aryl aldehydes were examined under similar conditions. The best result was obtained with pentafluorobenzaldehyde, due to the stabilities of both intermediate expanded porphyrinogens on acidolysis and expanded porphyrins on oxidation. ${ }^{12}$ Hence, formation of expanded porphyrins occurs only with electron-deficient aryl aldehydes (table 3). ${ }^{16}$

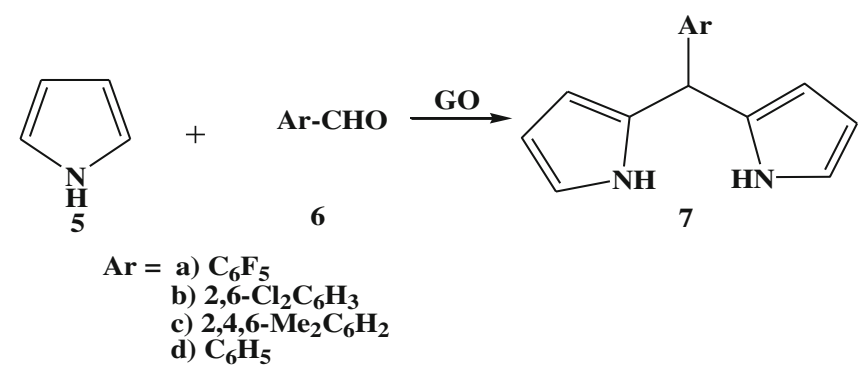

Figure 1. Synthesis of dipyrromethane using solid graphite oxide.

\subsection{Formation of symmetrical meso-substituted} porphyrins, expanded porphyrins and mixed porphyrins

Reaction of dipyrromethane $7 \mathbf{a}$ (figure 1) with $\mathbf{6 a}$ afforded porphyrin and expanded porphyrins selectively with only even number of pyrrole units in higher yields at room temperature itself (scheme 4) while with other acids such as methane sulfonic acid and $p$ toluenesulfonic acid such selectivity is observed only at $0{ }^{\circ} \mathrm{C}$ (table 4). ${ }^{27}$

A high yield of meso-pentafluorophenyl substituted hexaphyrin was obtained when catalyst loading (4) was $7.5 \mathrm{wt} \%$ (figure 2). The catalyst 4 was reusable up to five runs after which yields were decreased to almost half (figure 3). Raman spectrum of recovered catalyst 4 showed red shifting in the $\mathrm{D}$ and $\mathrm{G}$ bands with increased $\mathrm{I}_{\mathrm{D}} / \mathrm{I}_{\mathrm{G}}$ ratio, which was attributed to the presence of carbonaceous byproducts such as polymeric materials on the surface of the catalyst (figures S19, S20), hence resulting in decreased reactivity. ${ }^{26}$ A higher catalytic turnover number $(\mathrm{TON}=133)$ and non-toxicity, proves 4 to be a better catalyst.

\subsection{Non-covalent interaction of porphyrinoids with pristine graphene in organic solvents}

The absorption spectroscopy and fluorescence is an important technique to study the non-covalent interactions of porphyrinoids with planar organic molecules. ${ }^{28-30}$ Porphyrins are known to interact with various carbon materials, such as graphite, fullerenes and carbon nanotubes (CNTs), through $\pi$-stacking between their electron-abundant aromatic cores and

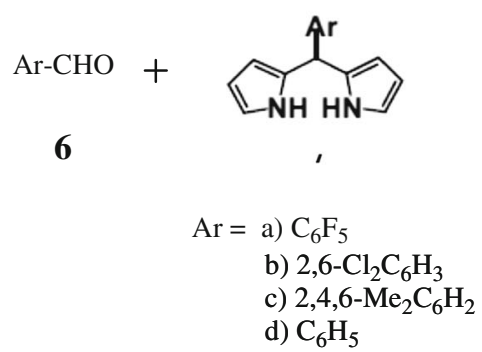

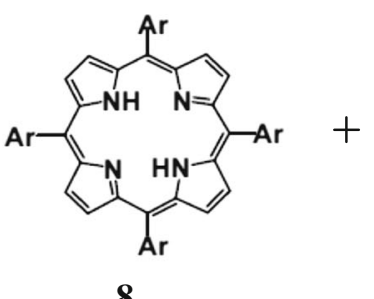

8

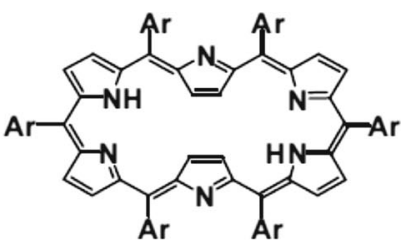

10

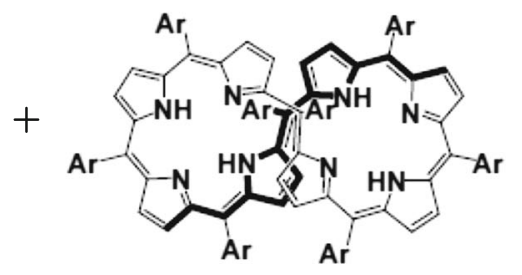

11

Scheme 4. Synthesis of porphyrinoids in the presence of sulfonated graphene 4 using dipyrromethane. 
Table 4. Reaction of 5-aryl dipyrromethane and different aryl aldehyde in o-dichlorobenzene using catalyst $\mathbf{4}^{\text {[a] }}$

\begin{tabular}{llll}
\hline Entry & Dipyrromethane & Aldehyde & Product Distribution (\% Yield) ${ }^{[\mathrm{b}],[\mathrm{c}]}$ \\
\hline 1 & $7 \mathrm{a}$ & $6 \mathrm{a}$ & $8 \mathrm{a}(16), 10 \mathrm{a}(28), 11 \mathrm{a}(10)$ \\
2 & $7 \mathrm{~b}$ & $6 \mathrm{~b}$ & $8 \mathrm{~b}(19), 10 \mathrm{~b}(10), 11 \mathrm{~b}($ traces $)$ \\
3 & $7 \mathrm{a}$ & $6 \mathrm{~b}$ & $8 \mathrm{ab}(4), 10 \mathrm{ab}(6)$ \\
\hline
\end{tabular}

[a] Reaction was conducted under inert atmosphere, reaction time: $2 \mathrm{~h}, \mathrm{rt}$. [b] 8: porphyrin, 10: hexaphyrin, 11: octaphyrin. [c] Isolated yields.

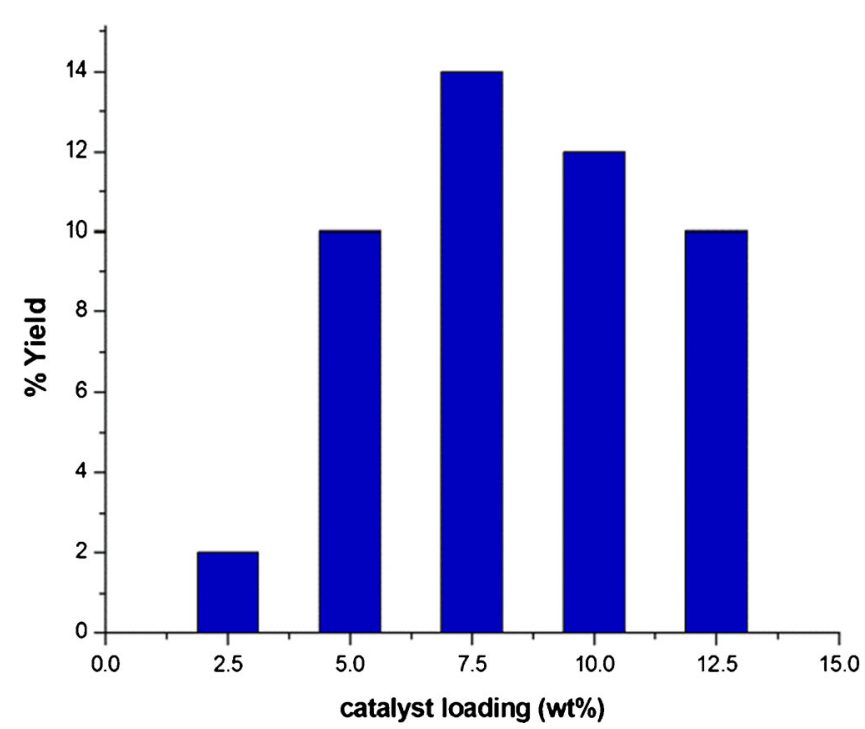

Figure 2. Effect of catalyst loading (sulfonated graphene 4) on the yield on hexaphyrin as listed in Table 1 .

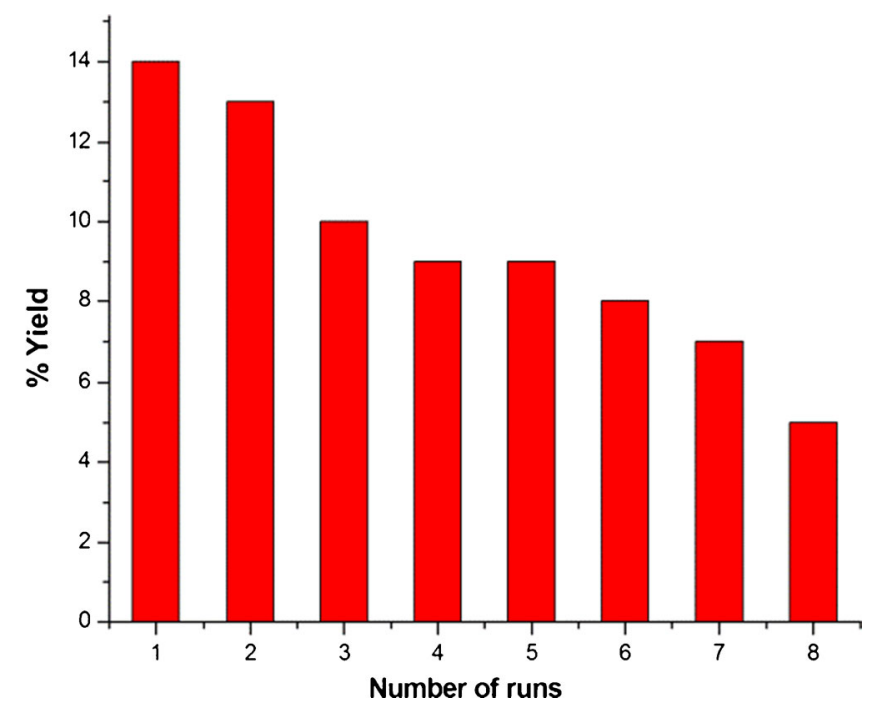

Figure 3. Yield of hexaphyrin from recycling runs of sulfonated graphene $\mathbf{4}$ as listed in Table 1.

conjugated surfaces of the carbon materials. ${ }^{31,32}$ The energy of non-covalent adsorption of solvents such as dimethylformamide (DMF), $o$-dichlorobenzene

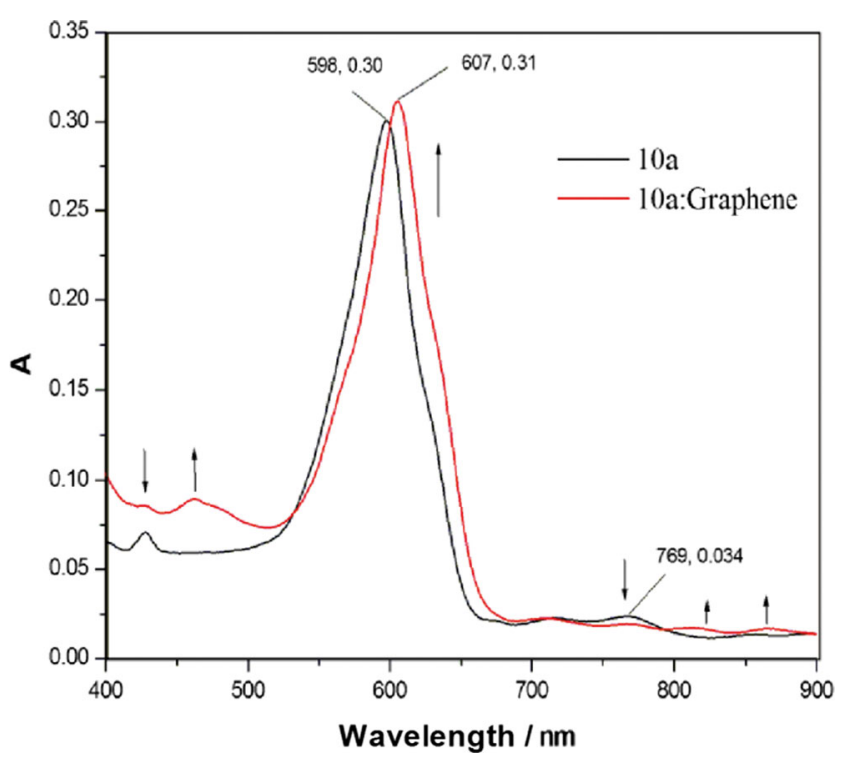

Figure 4. Absorption spectral changes of [28]hexaphyrin 10a on addition of graphene in o-DCB.

(o-DCB), N-methylpyrrolidine (NMP) and 1,2,4trichlorobenzene, is responsible for graphite exfoliation and stabilization of individual sheets of graphene. ${ }^{33}$

\section{5a Absorption spectra measurements (table 5):} The UV-Visible spectra of aromatic porphyrins with the addition of graphene, show a minor decrease in intensity with no new absorption bands indicating very small ground state interaction (figure S21). ${ }^{34} 28 \pi$ hexaphyrin (anti-aromatic) 10a, showed red shifted soret bands from 598 to $607 \mathrm{~nm}$ with increased intensity in o-DCB with addition of graphene (figure 4). This red shifting indicated J-type aggregate of antiaromatic hexaphyrin with graphene. This type of result was also observed with anti-aromatic pentaphyrin (figure 5). Such type of non-covalent interaction may be used in the development of sensors, detection of heavy metals and other newer materials. The noncovalent interaction of porphyrinoids with graphene sheets resulted into the formation of supramolecular dyads. ${ }^{35}$ 
Table 5. Absorption Spectral measurements of various porphyrinoids with pristine graphene.

\begin{tabular}{lcccc}
\hline Entry & porphyrinoid & solvent & $\begin{array}{c}\text { Absorption peak } \\
\text { (without addition) }\end{array}$ & $\begin{array}{c}\text { Absorption peak } \\
\text { (after addition) }\end{array}$ \\
\hline 1 & Porphyrin 8a (Fig S21) & o-DCB & 418 & 418 (minor difference in intensity) \\
2 & N-fused Pentaphyrin 9a (Fig 5) & o-DCB & 462 & 465 (increase in intensity) \\
3 & [26]Hexaphyrin 10a (Fig 4) & o-DCB & 572 & 573 \\
& & NMP & 605 & 601 (increase in intensity) \\
4 & [26]Hexaphyrin 10b (Fig S22) & o-DCB & 572 & 577 (decrease in intensity + new peak at 605) \\
4 & [28]Hexaphyrin 10a (Fig 4) & o-DCB & 598 & 607 (increase in intensity) \\
\hline
\end{tabular}

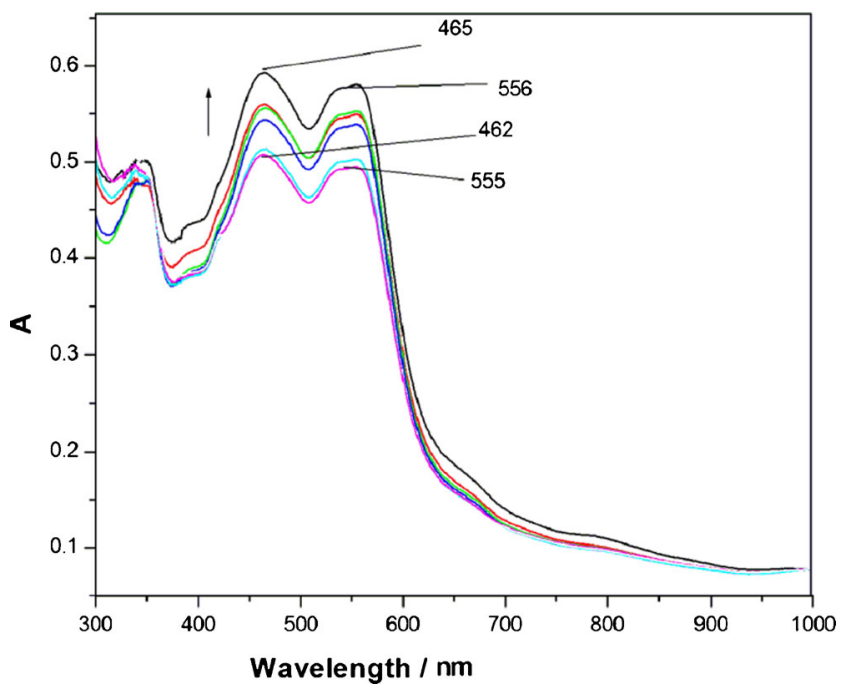

Figure 5. UV-Visible spectra of [24] N-fused pentaphyrin 9a $(1 \mu \mathrm{M})$ on increasing addition of exfoliated graphene $\left(0.25 \mathrm{mg} . \mathrm{mL}^{-1}\right)$ in $o$-DCB.

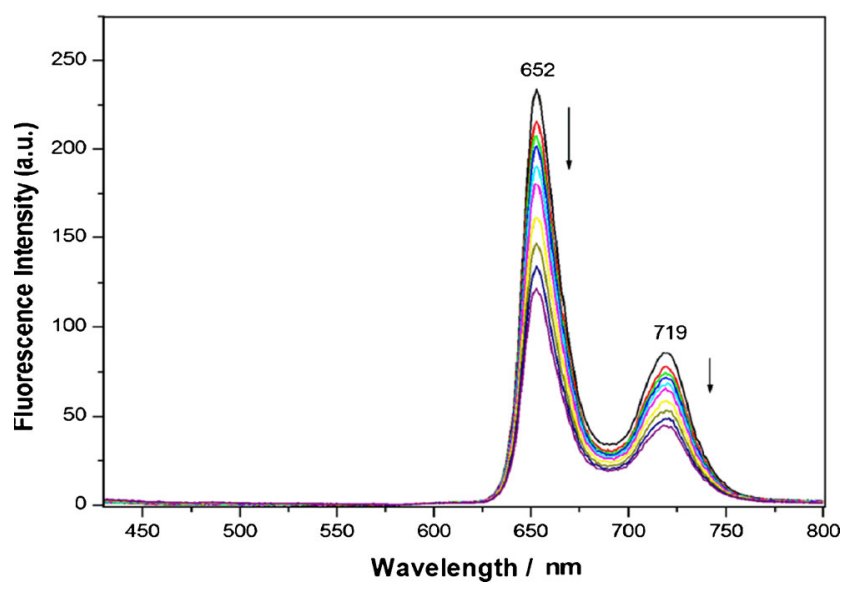

Figure 6. Quenching of the steady-state fluorescence intensities of 5,10,15,20-tetraphenylporphyrin $\mathbf{8 d}(1 \mu \mathrm{M})$ on increasing addition of exfoliated graphene $\left(0.25 \mathrm{mg} . \mathrm{mL}^{-1}\right)$ in $o-\mathrm{DCB}, \lambda \mathrm{ex}=420 \mathrm{~nm}$.

3.5b Fluorescence spectra measurements (table 6): Unlike the absorption spectra, fluorescence spectra of
Table 6. Fluorescence spectral measurements of various porphyrinoids with pristine graphene.

\begin{tabular}{lccc}
\hline Entry & Porphyrinoid & Solvent & $\begin{array}{c}\text { Fluorescence } \\
\text { quenching }\end{array}$ \\
\hline 1 & $8 \mathrm{a}$ & o-DCB & $30 \%$ \\
2 & $8 \mathrm{~b}$ & o-DCB & $30 \%$ \\
3 & $8 \mathrm{c}$ & o-DCB & $40 \%$ \\
4 & $8 \mathrm{~d}$ & o-DCB & $50 \%$ \\
\hline
\end{tabular}

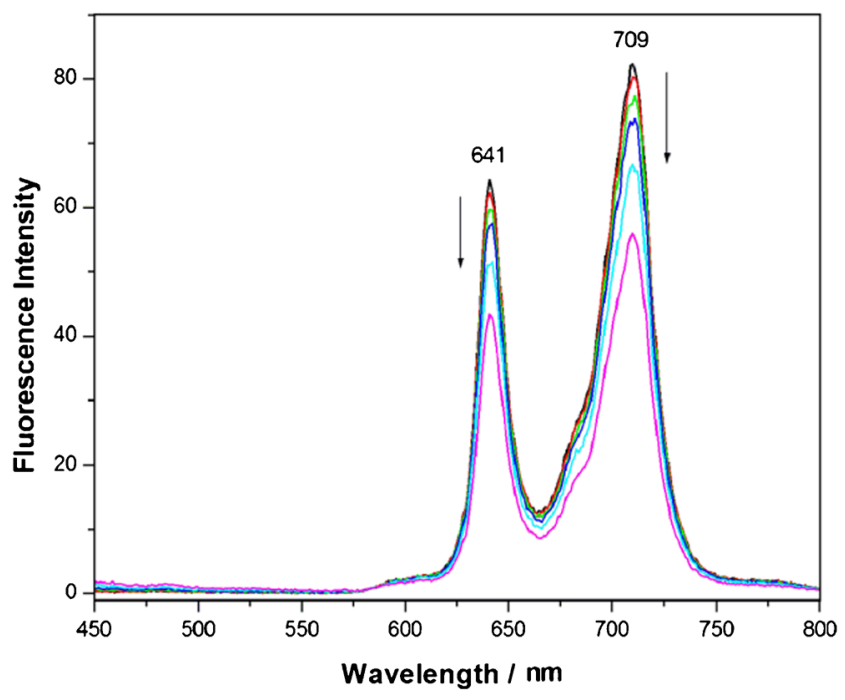

Figure 7. Quenching of the steady-state fluorescence intensities of 5,10,15,20-tetra-(2',3',4',5',6'pentafluorophenyl)porphyrin $\mathbf{8 a}(1 \mu \mathrm{M})$ on increasing addition of exfoliated graphene $\left(0.25 \mathrm{mg}\right.$. $\left.\mathrm{mL}^{-1}\right)$ in $o$-DCB, $\lambda_{\mathrm{ex}}=418 \mathrm{~nm}$.

porphyrins show remarkable changes on the addition of pristine graphene solution in o-DCB. The intensity of the fluorescence bands were quenched up to $50 \%$ on addition of graphene in case of porphyrins with electron donating substituents at meso position (figure 6), whereas those with electron withdrawing substituent (figure 7, S23), 15-30\% quenching was observed. The quenching of fluorescence could be ascribed to the $\pi-\pi$ interaction of porphyrin and graphene. 


\section{Conclusions}

The high catalytic activity and turnover number in the synthesis of meso-aryl porphyrins and expanded porphyrins catalyzed by sulfonated graphenes have been observed in dichloromethane and o-dichlorobenzene. The cross-condensation of dipyrromethane with aldehyde gave cross products in better yield at room temperature. The formation of porphyrinoids may be explained by $\mathrm{C}-\mathrm{C}$ bond formation and oxidation reactions catalyzed by sulfonated graphene. The use of heterogeneous carbocatalyst led to increased yields of product and reusability of catalyst several times. The red shifted soret bands and quenching of fluorescence intensity revealed the $\pi-\pi$ interaction between porphyrinoids and pristine graphene.

\section{Supporting Information}

Characterization of catalysts and synthesized compounds using TEM, SEM, Raman, FTIR, powder XRD, TGA, UV-Vis, ${ }^{1} \mathrm{H}$ NMR, ${ }^{13} \mathrm{C}$ NMR and ESIMS have been provided. Titration studies using UV-Vis and steady state fluorescence spectroscopy have been given. Figures S1-S23 and other results are reported in Supplementary Information which is available at www. ias.ac.in/chemsci.

\section{Acknowledgements}

The authors gratefully acknowledge the Council of Scientific and Industrial Research (CSIR), New Delhi, University Grants Commissions (UGC), New Delhi, for financial assistance and USIC, University of Delhi, for material characterization.

\section{References}

1. Rao C N R, Sood A K, Subrahamanyam K S and Govindaraj A 2009 Angew. Chem. 1217890

2. Potts J R, Dreyer D R, Bielawski C W and Ruoff R S 2011 Polymer 525

3. Wang G, Yang J, Park J, Gou X, Wang B, Liu H and Yao J 2008 J. Phys. Chem. C 1128192

4. Rodriguez-Perez L, Herranza M A and Martin N 2013 Chem. Comm. 493721

5. Dreyer D R, Jia H Pand Bielawski C 2010 Angew. Chem. 1226965

6. Jia H P, Dreyer D R and Bielawski C W 2011 Tetrahedron 674431

7. Lotya M, Hernandez Y, King P J, Smith R J, Nicolosi V, Karlsson L S, Blighe F M, De S, Wang Z, McGovern
I T, Duesberg J S and Coleman J N 2009 J. Am. Chem. Soc. 1313611

8. Kuilaa T, Bosea S, Mishra A K, Khanraa P, Kimc N H and Lee J H 2012 Prog. Mater. Sci. 571061

9. K M Kadish, K M Smith and R Guilard (eds.) In Handbook of Porphyrin Science 2010 (Singapore: World Scientific Publishing)

10. Mishra R and Chandrashekhar T K 2008 Acc. Chem. Res. 41265

11. Jasat A and Dolphin D 1997 Chem. Rev. 972267

12. Saito $\mathrm{S}$ and Osuka A 2011 Angew. Chem. Int. Ed. 50 4342

13. Shin J-Y, Furuta H, Yoza K, Igarashi S and Osuka A 2001 J. Am. Chem. Soc. 1237190

14. Neves M G P M S, Martins R M, Tomé A C, Silvestre A J D, Silva A M S, Félix V, Drew M G B and Cavaleiro J A S 1999 Chem. Comm. 385

15. Kim K S, Yoon Z S, Ricks A B, Shin J-Y, Mori S, Sankar J, Saito S, Jung Y M, Wasielewski M R, Osuka A and Kim D J 2009 Phys. Chem. A 1134498

16. Suzuki M and Osuka A 2003 Org. Lett. 53943

17. Alonso M, Geerlings P and Proft F D 2013 J. Org. Chem. 784419

18. Stepien M and Latos-Grazynski L 2009 Top Heterocycl. Chem. 1983

19. Chauhan S M S and Mishra S 2011 Molecules 167256

20. Sharma R, Baik J H, Perera C J and Starno M S 2012 Nano Letts. 10398

21. Liang C, Huang J F, Li Z, Luo H and Dai S A 2006 Eur. J. Org. Chem. 586-589

22. Hong J Y, Shin K Y, Kwon O S, Kang H and Jang H 2011 Chem. Comm. 477182

23. Ferrari A C, Meyer J C, Scardaci V, Casiraghi C, Lazzeri M, Mauri F, Piscanec S, Jiang D, Novoselov K S, Roth S and Geim A K 2006 Phys. Rev. Letts. 97187401

24. Si Y and Samulski E T 2008 Nano Letts. 81679

25. Liang J, Xu Y, Huang Y, Zhang L, Wang Y, Ma Y, Li F, Guo T and Chen Y 2009 J. Phys. Chem. C 1139921

26. Lam E, Chong J H, Majid E, Liu Y, Hrapovic S, Leung A C W and Luong J H T 2012 Carbon 501033

27. Taniguchi R, Shimizu S, Suzuki M, Shin J Y, Furuta H and Osuka A 2003 Tetrahedron Lett. 442505

28. Bi C, Li Y, Chen H, Yin G and Zhu J 2012 Chin. J. Chem. 301722

29. Miguel M D, Alavaro M and Garcia H 2012 Langmuir 282849

30. Rodriguez-Perez L, Herranza M A and Martin N 2013 Chem. Comm. 493721

31. Hasobe T, Imahori H, Kamat P V, Ahn T K, Kim, Kim D, Fugimoto A, Hirakawa T and Fukuzumi S $2005 \mathrm{~J}$. Am. Chem. Soc. 1271216

32. Boyd P D W and Reed C A 2005 Acc. Chem. Res. 38 235

33. Geng J, Kong B -S, Yang S B and Jung H T 2010 Chem. Comm. 465091

34. Malig J, Stephenson A W I, Wagner P, Wallace G G, Officer D L and Guldi D M 2012 Chem. Comm. 488745

35. Zhou J, Chen M and Diao G 2013 ACS Appl. Mater. Interfaces $\mathbf{5} 828$ 